requires $\mathrm{C}=66.6$; $\mathrm{H}=8.0$; mol. weight $=252$; $\mathrm{CH}_{3}-(\mathrm{C})=5.9$ for 1 ; active $\mathrm{H}=1.2$ for 3 . It remains to confirm this formula by the preparation of a derivative.

Frequentin is fairly soluble in acetone and dioxane, somewhat less soluble in chloroform, ethanol and benzene, and only slightly soluble in carbon tetrachloride and water. The compound is markedly surface active, and aqueous solutions froth readily. The compound decolorizes a solution of bromine in glacial acetic acid. It is an aldehyde; on adding it to a solution of $1: 4$ dihydroxynaphthalene in acetic acid, then adding two drops of concentrated hydrochloric acid, and boiling for one minute, a deep red-violet colour appears ${ }^{3}$. It reduces ammoniacal silver oxide and gives a positive Schiff's test. It does not liberate carbon dioxide from sodium bicarbonate solution; but it dissolves in sodium carbonate solution. Frequentin gives a magenta colour with ferric chloride.

These analyses and properties suggest that frequentin $\left(\mathrm{C}_{14} \mathrm{H}_{20} \mathrm{O}_{4}\right)$ and palitantin $\left(\mathrm{C}_{14} \mathrm{H}_{22} \mathrm{O}_{4}\right)$ may be closely related. Work is in progress to investigate any such relationship.

The stability in aqueous solution at $25^{\circ} \mathrm{C}$. was examined by means of spore germination assays ${ }^{4}$. At $p \mathbf{H ~ 3 - 5}$ and 5 the loss of activity was 5 per cent per day; but at $p H 7$ the loss increased to 20 per cent.

Germination of the conidia of Botrytis allii is prevented by $2 \cdot 5 \mu \mathrm{gm} . / \mathrm{ml}$. at $p \mathrm{H} \cdot 3 \cdot 5$. It shows the same order of activity against Penicillium gladioli, Stachy. botrys atra and Mucor mucedo; but 25-50 $\mu \mathrm{gm} . / \mathrm{ml}$. is needed to inhibit germination of Absidia glauca and Aspergillus niger.

In broth, the minimum concentration required to inhibit and kill Staphylococcus aureus was $300 \mu \mathrm{gm}$. $\mathrm{ml}$. , and Bacillus subtilis $200 \mu \mathrm{gm} . / \mathrm{ml}$., but no effect was observed on Bacterium coli at $400 \mu \mathrm{gm} . / \mathrm{ml}$. Bacterium globiforme was inhibited but not killed by $200 \mu \mathrm{gm} . / \mathrm{ml}$.

We are indebted to Messrs. W. Brown and H. R. Thomas, of these Laboratories, and Drs. G. Weiler and F. B. Strauss, Oxford, for microanalyses.

$$
\begin{aligned}
& \text { P. J. CuRtis } \\
& \text { H. G. Hemming } \\
& \text { W. K. SMith }
\end{aligned}
$$

Butterwick Research Laboratories,

Imperial Chemical Industries, Ltd.,

$$
\text { Welwyn, Herts. }
$$$$
\text { Nov, } 30 .
$$

${ }^{1}$ Brian, P. W., and Grove, J. F. (unpublished work).

- Birkinshaw, J. H., and Raistrick, H., Biochem. J., 30, 801 (1936).

'Raudnitz, H., and Puluj, G., Ber. dtsch. chem. Ges,, 64, 2214 (1931).

- Brian, P. W., and Hemming, H. G., Ann. App. Biol., 32, 214 (1945).

\section{A Pink Yeast requiring Aneurin}

AN unidentified strain of 'pink yeast' (probably a species of Rhodotorula) isolated from brewer's finings grows well in a defined glucose-salts - ammonia medium in the absence of vitamins of the $\mathbf{B}$ complex, with the exception of aneurin. Up to $24 \mathrm{hr}$., the response to added aneurin is poor, this period presumably being that required for the phosphorylation of aneurin to its pyrophosphate; afterwards the response is marked, whereas controls containing no aneurin grow up poorly, even after $72 \mathrm{hr}$. of incubation.

For carbon sources, the organism favours glucose, fructose or sucrose, but can also utilize mannose, maltose, acid casein hydrolysate, fumarate and mal- ate. Galactose and raffinose are poor carbon sources, and mannitol, salicin, maleic acid and inositol cannot be utilized. Glucose is readily metabolized, but it is feebly fermented, if at all. Ammonium salts provide a suitable source of nitrogen, but the growth response curves to added aneurin are steeper if acid casein hydrolysate is also present in the basal medium. A $p \mathrm{H}$ of $4 \cdot 5-5 \cdot 5$ is suitable, but the organism grows well at $p \mathrm{H} 4 \cdot 0$. The relatively aerobic conditions obtained by incubation at $30^{\circ}$ in shallow layers $(8-\mathrm{ml}$. portions of medium in $25 \cdot \mathrm{ml}$. conical flasks) with continuous shaking give better response curves than do quiescent cultures in tubes. Using these aerobic conditions and a medium such as that described by Cutts and Rainbow ${ }^{1}$, but supplemented with acid casein hydrolysate, with aneurin omitted, and ad. justed to $p \mathrm{H} .4 \cdot 6$, growth is practically complete in $48 \mathrm{hr}$. Heavy crops of cells are obtained, and, for turbidity measurements with the Spekker absorptiometer, it is necessary to dilute ten times in order to obtain suitable readings. Over the range $0-2.5 \mathrm{~m} \mu \mathrm{gm}$. of aneurin hydrochloride per $\mathrm{ml}$., the response is approximately linear; but there is some indication that the curve may be slightly sigmoid. The response to other vitamins of the B group is slight, but sufficient to warrant their inclusion in the basal medium for aneurin assay purposes. The organism responds to the 'pyrimidine' but not to the 'thiazole' moiety of the aneurin molecule; however, the response to 'pyrimidine', on a weight-to-weight basis, is of the order of five times less than the response to aneurin hydrochloride.

Investigations are proceeding with the view of determining the suitability, or otherwise, of the organism for the microbiological assay of aneurin.

Department of Industrial Fermentation,

C. RAINBOW University,

Birmingham 15.

Nov. 17.

Cutts, N. S., and Rainbow, C., J. Gen. Microbiol., 4, 150 (1950).

\section{Serum Agglutinins in Brucellosis}

THOUGH the direct agglutination test in brucellosis is usually positive at a titre of $1 / 80$ or over, there is a small proportion of bacteriologically proved cases which fail to show direct agglutination at $a$ diagnostic titre with standard Brucella suspensions ${ }^{1,2}$. In addition, as is well known, there is a remarkable frequency of the prozone phenomenon in sera which give a positive Brucella agglutination test.

During the past six months, a number of sera from patients suspected of, or suffering from, brucellosis have been tested for 'incomplete' antibodies with a modified Coombs test ${ }^{3}$ and for 'blocking' antibodies', in addition to the routine direct agglutination reaction. To date, four cases of clinical brucellosis with a negative direct test (negative at $1 / 20-1 / 1280$ ) have shown, with the Coombs test, positive agglutination to $1 / 80$ or over (see table); it appears that the blocking titre, which has a rather indefinite end-point, is about four or five tubes lower than the Coombs titre. The blocking test, therefore, does not seem likely to prove of diagnostic value.

In five other cases showing a well-marked prozone at low dilutions with the direct test, the zone has been cut out in the Coombs test. The extent of a well-marked prozone does not appear to exceed the range of the blocking titre (see table). 